\title{
O mosquito da indiferença
}

\author{
Zika: do sertão nordestino à \\ ameaça global
}

DINIZ, Debora.

Rio de Janeiro: Civilização Brasileira, 2016, 191p.

"A história não é contada pelo lado de quem sofre, mas por quem tem a palavra para contá-la" (Debora DINIZ, 2016, p. 129). É por meio dessa inquietação que a antropóloga Debora Diniz (2016), professora de bioética na Faculdade de Direito da Universidade de Brasília, conta a história da epidemia do vírus zika no Brasil. Do Recife até o interior da Paraíba, do Rio Grande do Norte ao Rio de Janeiro e São Paulo, a autora foi ao encontro de quem viveu de perto o drama da doença misteriosa. Ela entrevistou médicos e cientistas e colheu narrativas de mulheres e homens do sertão nordestino que experimentaram a epidemia em seus corpos e em seu cotidiano. Reunindo os emergentes interesses dos estudos científicos, da saúde coletiva, dos estudos de gênero e do feminismo, em Zika: do sertão nordestino à ameaça global, Debora Diniz (2016) enlaça os caminhos da ciência euroamericana "universal" com os saberes clínicos de médicos de beira de leito e as histórias daquelas pessoas de biografias ignoradas - pais, mulheres grávidas e seus bebês desenganados. Histórias ouvidas num tempo de sofrimento e luta, que reconstroem um duplo cenário da epidemia do zika vírus no Brasil - o da sua identificação e o da descoberta da sua atuação na microcefalia dos fetos. Mais que isso, são histórias sobre silenciamentos e indiferenças em relação às mulheres, ao nordeste e à angústia e dor das pessoas que tiveram que aprender a viver junto com o mosquito num esquecimento que já dura décadas.

No primeiro capítulo, intitulado "Deu zika", Debora Diniz (2016) monta um quebra-cabeças que reconta a instalação do zika vírus no Brasil. Em um lugar do tempo situado entre alvoroços dos espetáculos do futebol - da Copa da Confederações de 2013 e a Copa do Mundo de 2014 - é que a história tem início. As incertezas, os diagnósticos desencontrados sobre a "alergia", "o vermelhão" ou "a dengue fraca" que começavam a se tornar cada vez mais frequentes, pipocavam em um grupo de whatsapp, o "Chikv, a missão", que reunia médicos e médicas do Rio Grande do Norte, da Paraíba, de Pernambuco, do Ceará e da Bahia. Nas mensagens trocadas entre esses "peregrinos do sertão", especialistas da clínica do cuidado investigando os corpos dos nordestinos anônimos que se ofereceram ao estudo, a descoberta da presença do zika vírus no Brasil era antecipada à ciência de bancada. Contudo, como mostra Debora Diniz (2016), a sua "validação" não viria sem desconfianças e descréditos. O que acontece é que desde mais de um século, de Cuba ao nordeste brasileiro, o Aedes aegypti opera também como um vetor do silenciamento científico. Há registros de epidemias de febre amarela e de dengue nas Américas desde três séculos e meio. Os amarelentos (Jaime Larry BENCHIMOL, 1992; 1999) e as vítimas da febre quebra-ossos (Denise Nacif PIMENTA, 2015), eram descritos como adoecidos pelos miasmas pestilentos que emanavam dos pântanos das cidades, pelo consumo da água suja ou pela degeneração física e moral dos amontoados urbanos. A ciência do século XIX apostava em fatores que incluíam a contaminação por contato e a difusão de germes pelo ar. Contudo, foi o médico cubano Dr. Carlos Finlay que passou a afirmar em 1881 que "a distribuição desta doença coincidia geograficamente e no tempo 
com a da atividade sazonal das fêmeas Aedes aegypti. Ele estimou, portanto, que o mosquito estava implicado na transmissão do hipotético agente da febre amarela" (Ilana LÖWY, 2006, p. 62). No entanto, houve uma indiferença de duas décadas em relação à sua descoberta, já que sua hipótese foi confirmada apenas no II Congresso Pan-Americano, quando o médico militar norte-americano, Dr. Walter Reed, apresentou seus relatórios. As críticas retroativas ao Dr. Finlay se centravam na ideia de que ele teria negligenciado o ciclo biológico do agente patológico no mosquito. Para ele, ao invés de um hospedeiro intermediário, o Aedes aegypti funcionaria como transmissor mecânico simples, como uma espécie de seringa. Mas, como sugere Nancy Stepan (1992) a questão é mais complexa do que as disputas em torno do rea papel do mosquito. Cuba, como o Nordeste brasileiro, está fora da geopolítica da grande ciência. Para essa autora, o trabalho do Dr. Finlay foi negligenciado pelo fato de ele ser cubano, por aquele ser um momento de disputa militar entre o seu país e os Estados Unidos e pela crença de que aquela era uma doença própria das colônias. A grande ciência que interessava à emergente medicina tropical da época se movia numa disputa entre os laboratórios do Instituto Pasteur em Paris ou naqueles que começavam a ser equipados em cidades dos Estados Unidos e do Brasil, com os fundos do $\mathrm{Sr}$. Rockefeller. Passado mais de um século, no Brasi do zika vírus, a voz da ciência está nos laboratórios do sudeste do país. Como afirma Debora Diniz (2016, p. 16), em meio às idas ao campo, ao encontro dos doentes que apareciam em número cada vez mais espantoso pelo sertão e os testes que apontavam para a presença de um novo vírus no país,

os nordestinos eram contestados por várias camadas de indiferença que organizam a sociedade brasileira - uma delas é regional; outra é o fato de que muitos deles eram clínicos, professores e cuidadores de gente doente, mas não cientistas nos termos quantificados pela ciência dos currículos das publicações internacionais e com o fator de impacto para o Prêmio Nobel de Medicina. [...] Os médicos que anunciavam a nova doença eram do nordeste, alguns da região do Cariri; a cena internacional projetava médicos brasileiros de beira de leito como descobridores de um novo adoecimento; as mulheres que adoeciam eram aquelas de quem ignoramos rostos e biografias em uma geopolítica da estratificação social (DINIZ, 2016, p. 13-16).
No segundo e no terceiro capítulos, intitulados "A primeira geração de mulheres" e "A microcefalia", Debora Diniz (2016) apresenta o protagonismo das mulheres grávidas no segundo movimento desse intenso tempo de descobertas - o da transmissão vertical do zika vírus (da gestante para o feto) e dos seus efeitos maléficos, a partir de 2015. Escutando as narrativas dessas nordestinas que sentiam que algo não estava bem com seus bebês, a história da microcefalia começava a ganhar forma e saltar para a ciência do mundo. Como mostra a autora, as Dra. Adriana, Dra. Vanessa e Dra. Ana, bem como as suas capacidades clínicas de observação e de escuta das mulheres, foram decisivas para contestar as dúvidas e explicações que comecavam a ser formuladas em torno da microcefalia. As hipóteses oficiais variavam da falsa correlação (quando um problema emergente passa a servir de base - muitas vezes falsa para explicação de outros) às desconfianças de subnotificação de casos (que fizeram emergir controvérsias em torno da medida encefálica dos recém nascidos). É quando a Dra. Adriana - que não entendia o porquê das descobertas em torno do zika vírus terem saltado dos mosquitos para os bebês - se pergunta: "onde estavam as mulheres?". Ouvir as mulheres que chegavam às dezenas ao seu consultório e conseguir de algumas delas a permissão para a investigação do líquido amniótico foi o ponto decisivo para a nova descoberta. Contudo, novamente validada apenas após o crivo dos laboratórios de ponta do sudeste do país, que, àquela altura, já recebiam missões de pesquisadores do estrangeiro. Novamente, os silenciamentos. Como escreve Gabriel Pugliesi (2012, p. 241) a respeito das resistências do gênero subvertidas por Marie Curie - as materiais para sua pesquisa com a radioatividade e aquelas de sexo e de nacionalidade para a ciência "se a verdade fosse uma mulher, os filósofos a desconheceriam". Géssica, Conceição, Alda Adilma, Helena, ..., a Dra. Adriana, a Dra. Vanessa, a Dra. Ana - e tantas outras mulheres do Cariri, do Sertão e do Alto Sertão da Paraíba, "desconhecidas para a ciência dos homens das grandes cidades e universidades, mas que juntas souberam fazer as perguntas certas em momentos de intenso sofrimento" escrevem a história da ciência enquanto "viajam horas [para os hospitais e clínicas de fisioterapia da capital do Estado] para descobrir nos filhos o que a ciência ainda desconhece" (DINIZ, 2016, p. 80-81, acréscimo meu).

Finalmente, nos últimos três capítulos do livro - "O paciente zero", "O Sertão nordestino" e "A 
ameaça global" -, Debora Diniz volta a enfatizar a preeminência das pessoas que se fizeram cientistas pela vivência da epidemia no próprio corpo e que resistiram pela esperança. Aquela esperança tão central nas narrativas nordestinas - da flor do mandacaru, do tempo chuva. Mas, os silenciamentos operam por todos os lados: no tempo da crise políitca, das prisões por corrupção e dos novos corre-corres esportivos por conta dos Jogos Olímpicos, a epidemia foi esquecida. Mas, antes da epidemia, já se tinha esquecido o nordeste da escravidão, da casa grande e do engenho, da violência urbana crescente, dos problemas de infraestrutura pública e das mais de quatro décadas que o mosquito esperava pelo dia em que o zika vírus iria chegar. Também se tem silenciado, como bem assinala Debora Diniz (2016), que para cada recém-nascido com microcefalia é preciso que haja uma cuidadora disponível em tempo integral; que é preciso se deslocar para exames e estimulações; e que políticas sérias de saúde não podem se basea em abstinência sexual. O silenciamento em torno das políticas "mosquitocentradas" é outro sintoma de que ainda não temos olhado de maneira crítica para ações inócuas, baseadas em pesticidas contaminantes, ao invés práticas preventivas e orientadas ao ambiente e às infraestruturas. Aliás há que se perguntar também sobre o próprio silenciamento antropológico sobre o tema das contaminações associadas ao Aedes aegypti. Em um quadro recente, temos a chikungunya $e$ a febre e a síndrome congênita decorrentes do vírus zika. Mas, antes delas, recalcitrantes problemas com a dengue são rotina desde os anos de 1980. E em um cenário mais amplo, que inclui a febre amarela, contamos pelo menos com um século e meio de importantes questões de saúde pública associadas à presença desse mosquito. A pobreza da população - cultural, educacional socioeconômica - tem sido uma resposta crônica que suplanta a verdadeira pobreza, que é aquela dos sistemas de serviço público, como abastecimento adequado de água e o saneamento básico (Jean SEGATA, 2016).

Enfim, o livro de Debora Diniz (2016) é um exemplo bem sucedido de como os estudos antropológicos sobre as crises sanitárias nos permite compreender estratégias para o governo das populações humanas (e outras espécies, como os mosquitos e os vírus) e dos ambientes. Trabalhos como este colocam em evidência dilemas transnacionais, como os que envolvem a responsabilidade sobre as contaminações, as relações entre as infecções e as economias e mercados, além dos hiatos entre as políticas científicas universais e as práticas locais. Escrevendo a história de uma epidemia a partir das narrativas de quem a viveu, a autora nos coloca diante de muitas indiferenças, já que em uma outra face das inovações e descobertas científicas aparece o sofrimento e $o$ anonimato de quem carrega as marcas dos efeitos perversos do descaso e da falta de políticas públicas mais abrangentes. Assim, Zika: do sertão nordestino à ameaça global é uma crítica sobre o gênero e a geografia política e moral das vozes da ciência e uma importante reflexão sobre a forma como a pobreza foi transformada em uma estratégia de ocultamento dos problemas estruturais, das mais diversas naturezas, neste Brasil das desigualdades. Para mais além do que isto, este é um livro sobre vidas que importam.

\section{Referências}

BENCHIMOL, Jaime Larry. A cidade pestilenta: a medicina social e o espaço urbano. In:

Pereira Passos - um Haussmann tropical: a renovação urbana do Rio de Janeiro no início do século $X X$. 2.ed. Rio de Janeiro: Secretaria Municipal de Cultura, Turismo e Esportes, 1992, p. 112-123.

Dos micróbios aos mosquitos: febre amarela e a revolução pasteuriana no Brasil. Rio de Janeiro, EdUfRJ/Editora Fiocruz, 1999.

DINIZ, Debora. Zika: do sertão nordestino à ameaça global. Rio de Janeiro: Civilização Brasileira, 2016.

LÖWY, llana. Virus, mosquitos e modernidade: a febre amarela no Brasil entre ciência e política. Rio de Janeiro: Editora Fiocruz, 2006.

PIMENTA, Denise Nacif. A (des)construção da dengue: de tropical a negligenciada. In: VALLE, Denise; PIMENTA, Denise Nacif; CUNHA, Ricardo Venâncio de (Orgs.). Dengue: teorias e práticas. Rio de Janeiro: Editora Fiocruz, 2015, p. 23-59.

PUGLIESI, Gabriel. Sobre o "Caso Marie Curie": a radioatividade e a subversão do gênero. São Paulo: Alameda, 2012.

SEGATA, Jean. "A doença socialista e o mosquito dos pobres". Iluminuras, 17(42), p. 372-389, 2016.

STEPAN, Nancy. "The interplay between socioeconomic factors and medical research: yellow fever research, Cuba and the United States". Social Studies of Science, 8(4): p. 397423, 1978.

[Recebida em 02/10/2016 e aceita em 07/02/2017] 
Jean Segata

Universidade Federal do Rio Grande do Sul, Porto Alegre, Rio Grande do Sul, Brasil

Jean Segata (jeansegata@ufrgs.br) é Professor Adjunto do Departamento de Antropologia e do Programa de Pós-Graduação em Antropologia Social da UFRGS. Possui mestrado e douto- rado em Antropologia Social pela UFSC, onde também realizou pós-doutorado. Tem experiência na área Antropologia Urbana e Teoria Antropológica, atuando principalmente nos seguintes temas/campos: redes sociotécnicas; ciência, tecnologia e sociedade; cibercultura; natureza e cultura; relações humano-animal em meios urbanos.

978 Estudos Feministas, Florianópolis, 25(2): 000, maio-agosto/2017 